\title{
Seasonal dynamics of the mysid Neomysis integer and its predation on the copepod Eurytemora affinis in a shallow hypertrophic brackish lake
}

\author{
Henning Fjord Aaser, Erik Jeppesen*, Martin Søndergaard \\ National Environmental Research Institute, Vejlsøvej 25, PO Box 314, DK-8600 Silkeborg, Denmark
}

\begin{abstract}
The study included field sampling, field experiments in enclosures and laboratory predation experiments. Neomysis integer, which underwent 2 generations during the study year (1992), occurred in high density, the maximum being 0.8 ind $\mathrm{l}^{-1}$ or $1250 \mathrm{ind} . \mathrm{m}^{-2}$. Estimated production was $2.2 \mathrm{~g}$ DW (dry wt) $\mathrm{m}^{-2} \mathrm{yr}^{-1}$ and peaked in August at $25 \mathrm{mg} \mathrm{DW} \mathrm{m}^{-2} \mathrm{~d}^{-1}$ The laboratory predation experiments revealed a high predation potential on Eurytemora affinis, the maximum predation rates on nauplii and copepodites + adults being 52 and 8 ind. mysid $^{-1} \mathrm{~h}^{-1}$, respectively. Stepwise multiple regressions on the data obtained from enclosure experiments conducted at various densities of $N$. integer and threespined sticklebacks Gasterosteus aculeatus revealed that the number of nauplii and the total number of $E$. affinis were significantly negatively related to the densities of both $N$. integer and fish, albeit positively to the interaction between fish density and $N$. integer density. In addition, the density of the advanced stages was significantly negatively related to that of fish, while the chlorophyll a concentration was weakly negatively related to $E$. affinis biomass and highly positively related to that of $N$. integer. The results provide further evidence that $N$. integer enhances eutrophication in nutrient-rich brackish lakes, i.e. N. integer predation on zooplankton reduces grazing pressure on the phytoplankton. Moreover, the results indicate that mysids also stimulate phytoplankton growth more directly.
\end{abstract}

KEY WORDS: Neomysis integer - Eurytemora affinis · Mysid · Copepod Predation - Brackish · Hypertrophic - Lake

\section{INTRODUCTION}

Invertebrate predation may have an important structuring impact on the zooplankton community in brackish as well as freshwater lakes (Hanazato 1990, Branstrator \& Lehman 1991), in particular when the abundance of vertebrate predators is low (Gliwicz \& Pijanowska 1989). Most mysids belong to the group of invertebrate predators, and prey on all sizes of rotifers, cladocerans and copepods (Arndt \& Jansen 1986, Hanazato 1990). Mysids are occasionally found in freshwater lakes, sometimes being artificially introduced to improve conditions for commercial fishing. In brackish lakes, in contrast, they are very common, and

·Addressee for correspondence. E-mail: fvms@dmu.dk often even abundant (e.g. Beattie \& de Kruijf 1978, Arndt \& Jansen 1986, Moss 1994, Jeppesen et al. 1994).

It is well known from freshwater lakes that the presence of mysids in high density may affect zooplankton composition and abundance (Goldman et al. 1979, Bowers \& Vanderploeg 1982, Fulton 1983, Langeland 1988, Hanazato 1990, Meijer et al. 1994), and recent research suggests that this may also be the case in brackish coastal areas (Rudstam et al. 1986, Hansson et al. 1990) and brackish lakes (Moss \& Leah 1982, Jeppesen et al. 1994). Jeppesen et al. (1994) found an inverse relationship between the density of fish and that of the mysid Neomysis integer (Leach). It was argued that the predation pressure by $N$. integer on zooplankton is particularly high in hypertrophic brackish lakes because fish biomass is low and dominated by sticklebacks, which are inefficient predators on $N$. integer. A 
further argument was that the availability of alternative food sources favoured this omnivorous species, thus keeping their density high even during periods of low zooplankton abundance and thereby maintaining a potentially high predation pressure on zooplankton. In contrast to this view, however, studies of a shallow eutrophic lake in the UK suggested that despite being present in high numbers, $N$. integer was unable to control the population of the dominant macrozooplankton, the copepod Eurytemora affinis (Irvine et al. 1993).

To further elucidate the structuring impact of Neomysis integer on the population of the dominant macrozooplankton Eurytemora affinis in a shallow hypertrophic brackish lake, we conducted a number of laboratory and in situ enclosure predation experiments and followed the seasonal dynamics of mysids and zooplankton for a $1 \mathrm{yr}$ period. In addition, we studied how the impact of $N$. integer on E. affinis was affected by the presence of threespined sticklebacks Gasterosteus aculeatus.

\section{MATERIALS AND METHODS}

Study area. The study was undertaken in Lake Ferring, a shallow brackish (salinity 3 to $6 \%$ ) lake situated in western Jutland, Denmark $\left(56^{\circ} \mathrm{N}, 8^{\circ} \mathrm{E}\right)$, about 100 to $200 \mathrm{~m}$ from the North Sea (Fig. 1). The lake area is $3.2 \mathrm{~km}^{2}$, and the mean and maximum depths are 1.5 and $2.6 \mathrm{~m}$, respectively. The lake is hypertrophic $\left(500 \mu \mathrm{g}\right.$ total-P $\left.^{-1}\right)$ with a high algal biomass and a low Secchi depth, i.e. less than $0.5 \mathrm{~m}$ throughout the year, the summer average being $0.25 \mathrm{~m}$ (M. Sondergaard unpubl. obs.). The phytoplankton was dominated by small-celled colonies of cyanobacteria, mainly Aphanothece spp. which comprised more than $90 \%$ of the total phytoplankton biomass. The mean summer phytoplankton biovolume was approximately $50 \mathrm{~mm}^{3}$ $\mathrm{l}^{-1}$. The fish community was dominated by threespined sticklebacks Gasterosteus aculeatus which, in terms of fish number, accounted for more than $95 \%$ of the total catch in a standardized test-fishing conducted in August with multiple mesh-size survey gill nets ranging from 6.25 to $75 \mathrm{~mm}$ (Sondergaard et al. unpubl. obs.).

Field sampling. Sampling was undertaken monthly between October and March 1992, and every 2 wk from April to September. Zooplankton were sampled with a 3.31 Patalas sampler at a mid-lake station, samples from depths of 0.2 and $1 \mathrm{~m}$ being pooled.

Mysid density in the lake was estimated by means of day time vertical hauls undertaken with a $500 \mu \mathrm{m}$ net (diameter $0.6 \mathrm{~m}$ ) at 21 stations (replicates from each station) positioned so as to represent the whole lake area (Fig. 1). The nets were lowered to the bottom and allowed to rest for 1 min before undertaking the haul. Preliminary investigations showed that mysid density was independent of whether the nets were allowed to rest for 1,2 or $5 \mathrm{~min}$. The samples were fixed in $96 \%$ ethanol.

A diurnal investigation on mysid density was carried out in September, when vertical hauls were made at 7 stations and Perspex Breder traps (Breder 1960) were positioned on the sediment surface at 12 locations for $2 \mathrm{~h}$ (4 in each of the transects, Nos. 1 to 3, Fig. 1). Sampling was performed in the afternoon $(15: 00 \mathrm{~h})$, at night (23:00 h) and in the morning after sunrise (08:00 h).

A qualitative investigation was made of the gut content of 20 mysids caught in net during the diurnal investigation, the food items being identified with the aid of a microscope at a magnification of 100 to $200 \times$.

Production and growth rates. The length-frequency distribution of Neomysis integer on each sampling date was estimated from length measurements of 75 mysids selected randomly from a pooled sample of the vertical hauls. Microscope images of the mysids were digitized using a video frame grabber and their length (measured from the tip of their rostrum to the end of their telson) determined on the computer from the digitized image. Mysid growth rates were estimated by studying the change in the average length of $N$. inte-

Fig. 1. Map of Lake Ferring showing depth contours, the locations of the 21 sampling stations and the 3 transects for incubation of plexiglass traps in the diurnal study (1 to 3 )

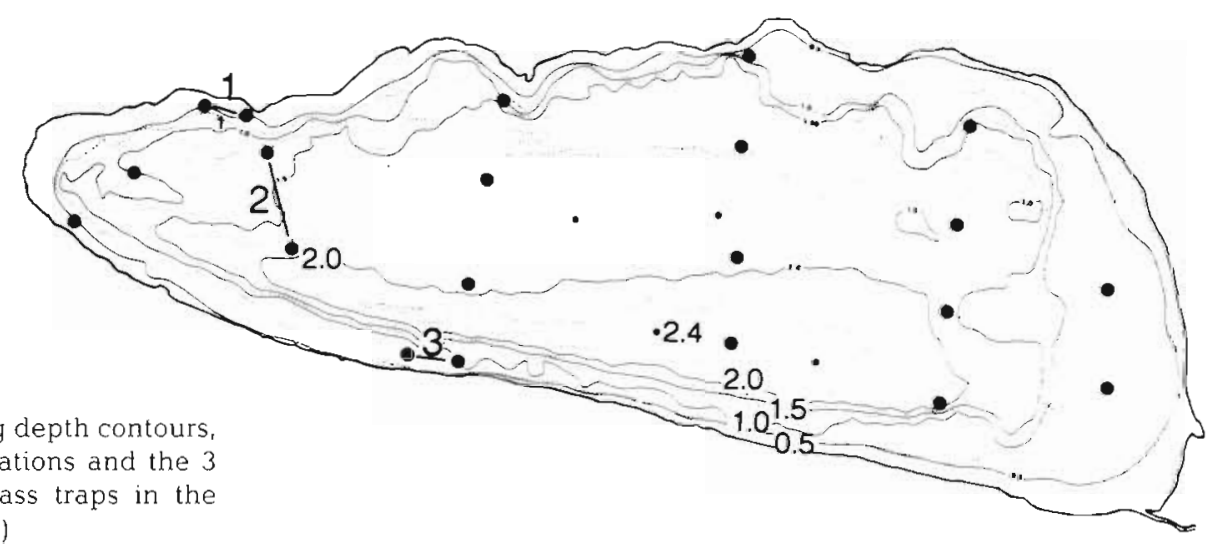


ger between sampling dates on cohorts from January to May, from late May to mid-July, and from mid-July to late October. To calculate mysid biomass and production the length-dry weight relationship (24 h at $60^{\circ} \mathrm{C}$ ) of mysids caught in January was used for the January to April samples, while that of mysids caught in August was used for August to December samples. In May and June, when both overwintering and summer generations were present simultaneously, the relationship for the combined data set was used. Mysid

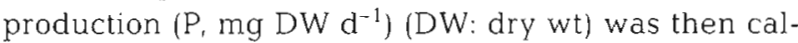
culated according to Bremer and Vijverberg (1982) as:

$$
\mathrm{P}=\sum_{i=1}^{n} \mathrm{P}_{i}
$$

where $\mathrm{P}$ is the daily population production, $\mathrm{P}_{i}=\Delta W_{1} \times$ $N_{i}$ and is the daily production by the $i$ th size class, $n$ is the number of size classes in the population, $W_{i}$ is the daily weight increase by the $i$ th size class, and $N_{i}$ is the population density of the $i$ th size class.

Eurytemora affinis biomass was calculated by applying a dry weight of $6.0 \mu \mathrm{g}$ ind.$^{-1}$ for females, $5.0 \mu \mathrm{g}$ ind $^{-1}$ for males, $2.0 \mu \mathrm{g}$ ind.$^{-1}$ for copepodites, and $0.5 \mu \mathrm{g}$ ind. ${ }^{-1}$ for nauplii (Bach et al. 1991). The somatic production (SP) for $E$. affinis was calculated according to Hirche (1992) as

$$
\mathrm{SP}=[\ln (W)-\ln (0.13)] / 10^{119636-0.04333 T 1}
$$

where $W$ is the average dry weight of adult copepods (5.5 $\mathrm{\mu g}$ ind. ${ }^{-1}$ assuming equal numbers of females and males) and $T$ is the water temperature $\left({ }^{\circ} \mathrm{C}\right)$.

Field enclosure experiments. Field experiments were carried out in 12 cylindrical enclosures made of tarpaulin sheets attached to a metal ring (diameter $1.5 \mathrm{~m}$, depth $0.75 \mathrm{~m}$ ). Each enclosure had a water volume of $1.3 \mathrm{~m}^{3}$ and was open to the sandy sediment at the bottom. The enclosures were organized in 3 sets of 4 enclosures. Prior to initiation of the experiments mysids were removed from one set using $500 \mu \mathrm{m}$ nets, and the density in the remaining 2 sets adjusted to approximately 0.5 and 1 ind. $\mathrm{I}^{-1}$, respectively. The stickleback Gasterosteus aculeatus density was adjusted randomly to one of 3 levels: $0-1,1-2$, and $2-5$ ind. $\mathrm{m}^{-2}$. Because of loss due to mortality, mysids were added to the enclosures at each sampling date to maintain the required experimental density.

Enclosure mysid density was determined from vertical hauls as described above, while stickleback density was determined from the catches in Breder traps placed at the bottom for $1 \mathrm{~h}$. We used the Zippin method to convert trap catches to enclosure density (Higgins 1985). In order to quantify zooplankton, $6.6 \mathrm{l}$ of water was sampled in the centre of each enclosure at a depth of $0.2 \mathrm{~m}$ using a 3.3 l Patalas sampler. The water was filtered through a $80 \mu \mathrm{m}$ filter and the specimens fixed in Lugols solution. Samples were taken twice weekly from July 22 to August 20. Backward stepwise multiple regression including date as a dummy variable was performed on all data from July 30 to August 20 ( 7 samples), thereby excluding the initial transitional phase, i.e. the first 8 d of the experiment. Eurytemora affinis was the only macrozooplankton recorded in the enclosures

Chlorophyll a (chl a) in the enclosures was measured according to the method of Holm-Hansen \& Riemann (1978) using water samples pooled from the same depths and at the same dates as described above.

The results from 3 of the 12 enclosures had to be excluded from the analysis, in 2 cases because the enclosure was damaged during a storm, and in the third case because the 'ecosystem' collapsed (the water became turbid, and all zooplankton and mysids disappeared within the first week).

Predation experiments. Laboratory experiments on Neomysis integer predation on Eurytemora affinis were carried out in $1 \mathrm{l}$ glass bottles. The mysids and copepods used were collected using 500 and $80 \mu \mathrm{m}$ nets, respectively. The mysids were allowed to acclimatize for $24 \mathrm{~h}$ in plastic holding tanks with approximately $10 \mathrm{l}$ of aerated Lake Ferring water and on a mixed diet of $E$. affinis and trout feed in the form of pellets. About $1 \mathrm{~h}$ prior to the experiment, mysids in sets of 3 were transferred to bottles containing 11 Lake Ferring water pre-filtered through a $50 \mu \mathrm{m}$ filter to remove copepods. The experiments were initiated by transferring either 100,200 or 400 nauplii and 100 copepodites + adults to the bottles. Three bottles served as controls. All experiments were conducted in aerated water in subdued light at $15^{\circ} \mathrm{C}$ and lasted $2 \mathrm{~h}$.

Following incubation the water was filtered through a $50 \mu \mathrm{m}$ filter and the mysids retained fixed in $96 \%$ ethanol and counted. The copepods were fixed in Lugol's solution and counted at a magnification of 25 to $50 \times$. The predation rate (PR, number mysid ${ }^{-1} \mathrm{~h}^{-1}$ ) was calculated as:

$\mathrm{PR}=\left(C_{\text {start }}-C_{\text {end }}\right) /($ number of mysids $\times$ incubation time $)$

$C_{\text {start }}$ and $C_{\text {end }}$ being the number of nauplii and copepodites + adults in the bottles before and after incubation, respectively. Clearance rates $\left(F, 1\right.$ mysid $\left.^{-1} \mathrm{~h}^{-1}\right)$ were calculated according to Gauld (1951) as:

$$
\begin{aligned}
F= & {\left[\left(\ln C_{\text {starl }}-\ln C_{\text {end }}\right) \times \text { litres }\right] / } \\
& \text { (number of mysids } \left.~^{-1} \times \text { incubation time }\right)
\end{aligned}
$$

and the preference value $(S)$ was estimated according to Chesson (1978) as:

$$
S=\left(R_{i} / P t_{i}\right) / \sum_{l=1}^{n}\left(R_{l} / P t_{i}\right)
$$

where $R_{i}$ is relative abundance of the $i$ th prey type in the food, $P t_{i}$ relative abundance of the $i$ th prey type in the environment, and $n$ total number of prey types. 


\section{RESULTS}

\section{Field data}

The average daytime catch of Neomysis integer in Lake Ferring increased in late May from a low winter level of approximately 100 ind $\mathrm{m}^{-2}$ to a maximum level of $1250 \mathrm{~m}^{-2}\left(0.8 \mathrm{l}^{-1}\right)$ in July followed by a decrease to a winter mean level of approximately $200 \mathrm{~m}^{-2}$ (Fig. 2). These values are conservative, however, as the diurnal investigation undertaken in September revealed that the number of mysids caught by vertical hauls was substantially and significantly ( $p<0.05$, Tukey's $t$-test) higher at night ( 1 ind. $\mathrm{I}^{-1}$ ) than in the morning and afternoon (approximately 0.27 ind. $\mathrm{l}^{-1}$ ) (Table 1). The higher catch during the night largely reflects migration from the bottom to the open water since the lake bottom Breder trap catch of mysids was significantly ( 2 to 3 times) greater during the day (average 360 ind. trap ${ }^{-1}$ ) than during the night (Table 1 ).

The first juvenile mysids were observed in midMay (Fig. 3). Recruitment continued until the end of October and was most intensive in mid-May, midJuly and mid-August. The mysids were approximately 2 to $3 \mathrm{~mm}$ when leaving the female marsupium, whereafter they grew to $17 \mathrm{~mm}$. Three cohorts were identified. From the changes in the average length of the different Neomysis integer cohorts (Fig. 4) the following semi-log transformed linear relationship between mysid length $(\mathrm{L}, \mathrm{mm})$ and growth rate $\left(\mathrm{GR}, \mathrm{mm} \mathrm{d}^{-1}\right)$ was established: January to April cohort: $G R=0.024(p<0.0001, n=5)$, May to July cohort: $G R=3.14 \times 0.567^{L}\left(r^{2}=0.82, p<0.03, n\right.$ $=5)$, August to December cohort: $G R=2.41 \times 0.538^{\mathrm{L}}$ $\left(\mathrm{I}^{2}=0.97, \mathrm{p}<0.001, \mathrm{n}=7\right)$.

Differential log transformed linear relationships between dry weight (DW, mg) and length ( $\mathrm{L}, \mathrm{mm}$ ) were found for the Neomysis integer caught in January (the winter generation): DW $=0.00347 \mathrm{~L}^{2.7046}\left(\mathrm{r}^{2}=0.98\right.$, $\mathrm{p}<0.0001, \mathrm{n}=50$ ), and for mysids caught in August (the summer generation): $\mathrm{DW}=0.00621 \mathrm{~L}^{24873}\left(\mathrm{r}^{2}=\right.$ $0.98, p<0.0001, n=50$ ). For the combined data set the relationship was $\mathrm{DW}=0.00638 \mathrm{~L}^{2.435}\left(\mathrm{r}^{2}=0.98, \mathrm{p}<\right.$ $0.0001, n=100$ ).

Table 1. Average catch of Eurytemora affinis $( \pm \mathrm{SD}$ ) in Breder traps $(n=12)$ and vertical hauls $(n=7)$ in Lake Ferring at 3 different times on 25 and 26 September 1992

\begin{tabular}{ccc|}
\hline $\begin{array}{c}\text { Time } \\
(\mathrm{h})\end{array}$ & $\begin{array}{c}\text { Breder traps } \\
(\text { mysids trap }\end{array}$ & $\begin{array}{c}\text { Vertical hauls } \\
{\left.\text { (mysids })^{-1}\right)}^{-1}\end{array}$ \\
\hline $15: 00$ & $360 \pm 346$ & $0.26 \pm 0.23$ \\
$23: 00$ & $132 \pm 78$ & $1.03 \pm 0.68$ \\
$08: 00$ & $268 \pm 110$ & $0.27 \pm 0.19$ \\
\hline
\end{tabular}

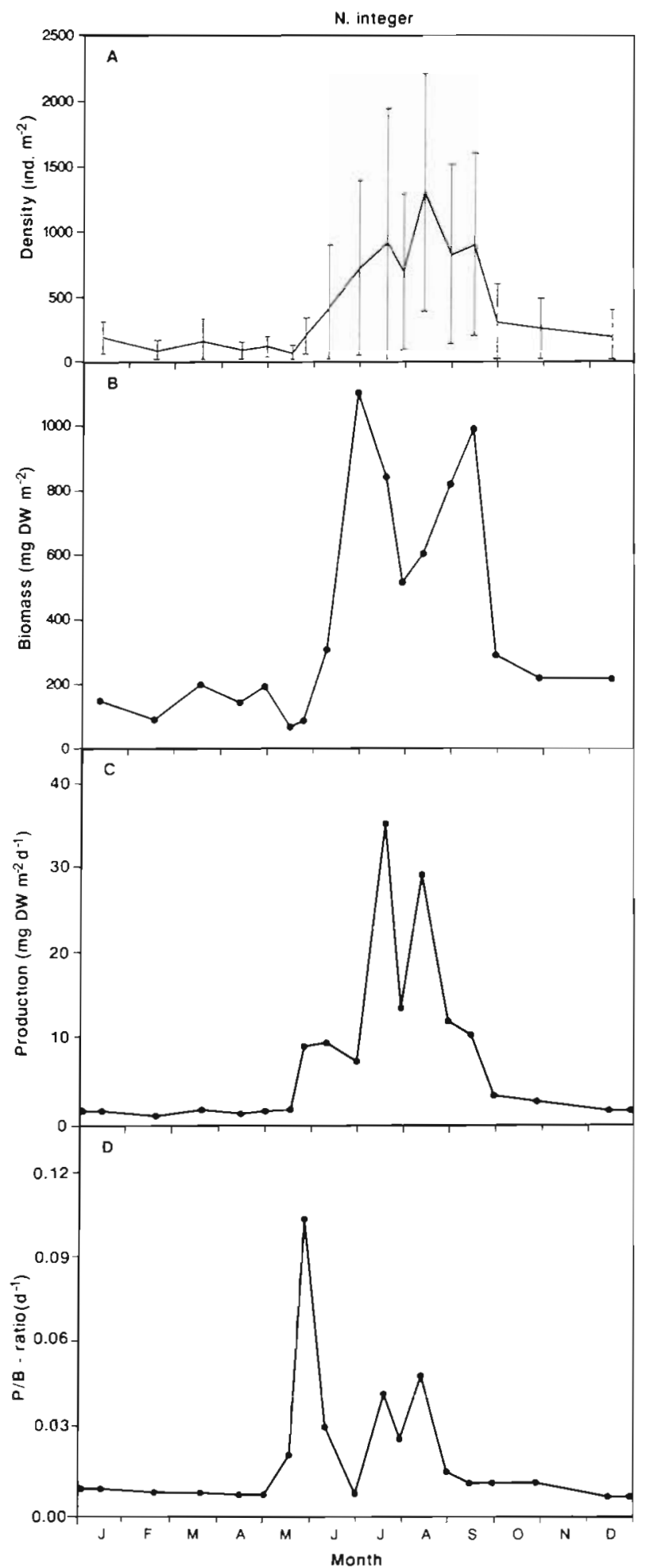

Fig. 2. Neomysis integer. Seasonal variation in (A) population density ( $\pm \mathrm{SD}, \mathrm{n}=21$ ), (B) biomass, (C) calculated production. and (D) P/B ratio in Lake Ferring in 1992

Mysid biomass increased from the end of May from low winter values of 100 to $200 \mathrm{mg} \mathrm{DW} \mathrm{m}^{-2}$ to maxi-

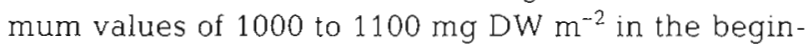



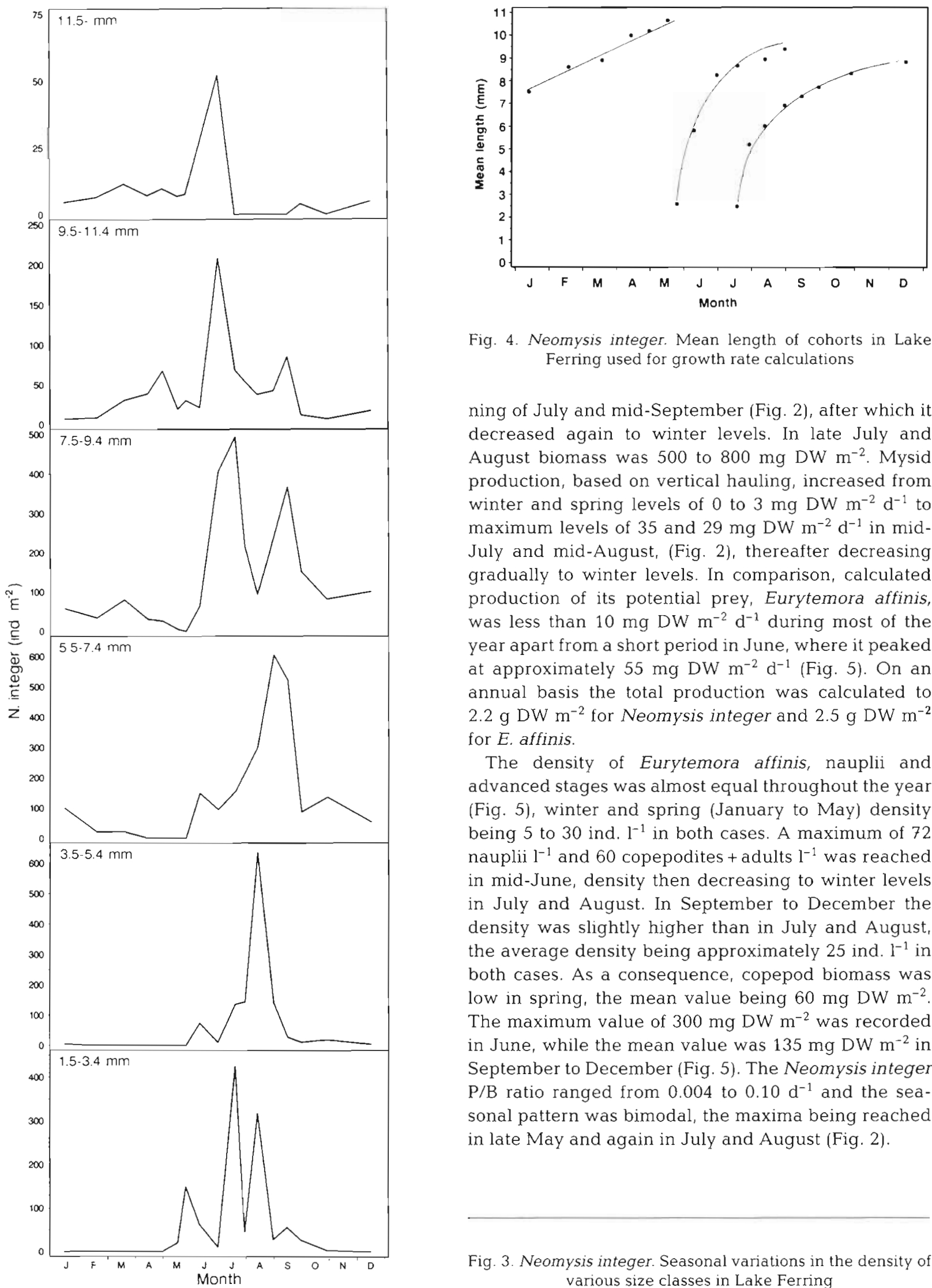

Fig. 4. Neomysis integer. Mean length of cohorts in Lake Ferring used for growth rate calculations

ning of July and mid-September (Fig. 2), after which it decreased again to winter levels. In late July and August biomass was 500 to $800 \mathrm{mg} \mathrm{DW} \mathrm{m} \mathrm{m}^{-2}$. Mysid production, based on vertical hauling, increased from winter and spring levels of 0 to $3 \mathrm{mg} \mathrm{DW} \mathrm{m}^{-2} \mathrm{~d}^{-1}$ to maximum levels of 35 and $29 \mathrm{mg} \mathrm{DW} \mathrm{m}^{-2} \mathrm{~d}^{-1}$ in midJuly and mid-August, (Fig. 2), thereafter decreasing gradually to winter levels. In comparison, calculated production of its potential prey, Eurytemora affinis,

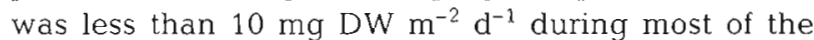
year apart from a short period in June, where it peaked

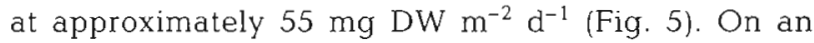
annual basis the total production was calculated to $2.2 \mathrm{~g} \mathrm{DW} \mathrm{m}^{-2}$ for Neomysis integer and $2.5 \mathrm{~g} \mathrm{DW} \mathrm{m}^{-2}$ for E. affinis.

The density of Eurytemora affinis, nauplii and advanced stages was almost equal throughout the year (Fig. 5), winter and spring (January to May) density being 5 to 30 ind. $\mathrm{l}^{-1}$ in both cases. A maximum of 72 nauplii $1^{-1}$ and 60 copepodites + adults $\mathrm{l}^{-1}$ was reached in mid-June, density then decreasing to winter levels in July and August. In September to December the density was slightly higher than in July and August, the average density being approximately 25 ind. $1^{-1}$ in both cases. As a consequence, copepod biomass was low in spring, the mean value being $60 \mathrm{mg} \mathrm{DW} \mathrm{m}^{-2}$.

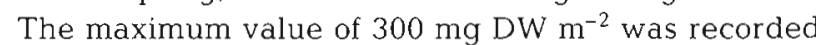
in June, while the mean value was $135 \mathrm{mg} \mathrm{DW} \mathrm{m}^{-2}$ in September to December (Fig. 5). The Neomysis integer $\mathrm{P} / \mathrm{B}$ ratio ranged from 0.004 to $0.10 \mathrm{~d}^{-1}$ and the seasonal pattern was bimodal, the maxima being reached in late May and again in July and August (Fig. 2).

Fig. 3. Neomysis integer. Seasonal variations in the density of various size classes in Lake Ferring 


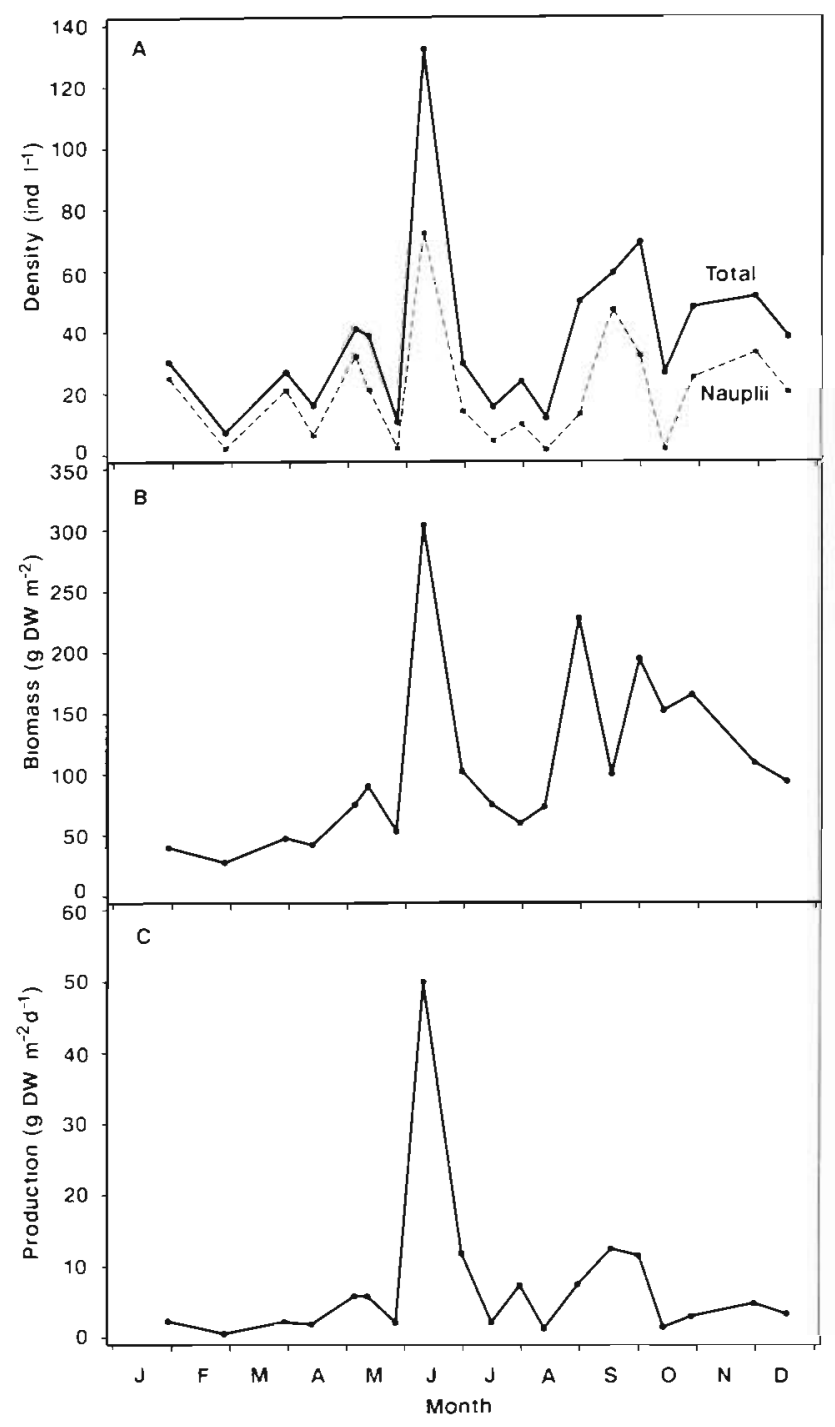

Fig. 5. Eurytemora affinis. Seasonal variation of (A) density (both total and naupliar), (B) biomass and (C) calculated production in Lake Ferring in 1992

\section{Enclosure experiments}

In the enclosure experiments marked changes in Eurytemora affinis density were found that followed changes in the density of Neomysis integer and Gasterosteus aculeatus. Average copepod density during the 25-day experiment varied from 295 ind. $\mathrm{l}^{-1}$ when the density of the mysids and sticklebacks was low (0.04 ind. $1^{-1}$ and 0.4 ind. $\mathrm{m}^{-2}$, respectively), to less than 100 when mysid density was high $\left(>0.25\right.$ ind. $\left.1^{-1}\right)$, in the latter case irrespective of stickleback density, which ranged from 0.25 to 4.2 ind. $\mathrm{m}^{-2}$ (Fig 6). Naupliar density decreased markedly at a mysid density of 0.1 ind. $\mathrm{I}^{-1}$, nauplii accounting for approximately $50 \%$ of the $E$. affinis population at the lowest $N$. integer
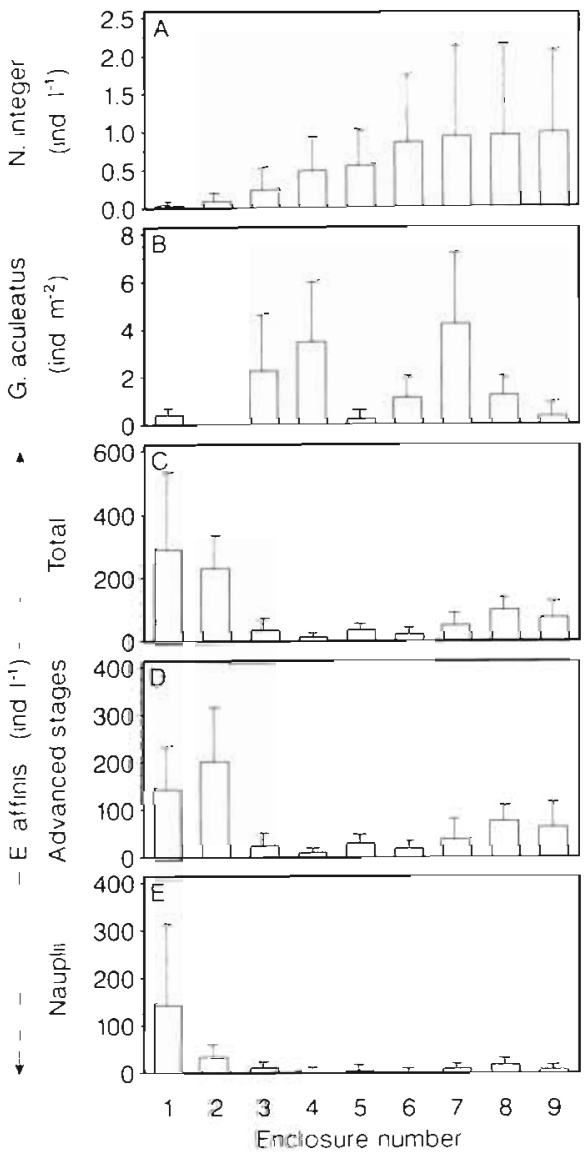

Fig. 6. Mean density (30 July to 20 August 1992) $( \pm \mathrm{SD}, \mathrm{n}=7$ ) of (A) Neomysis integer, (B) Gasterosteus aculeatus, and (C) total Eurytemora affinis, (D) E. affinis copepodites + adults and (E) E. affinis nauplii in the 9 field enclosures ordered by increasing mean $N$. integer density

density, but only 10 to $25 \%$ at higher $N$. integer densities. In accordance with this, nauplii density was significantly negatively correlated to $N$. integer density [Table 2; $\log (n+1)$ transformed data] In contrast, no relationship was detected between the density of mysids and that of copepodites + adults, although both nauplii and advanced stages of $E$. affinis were negatively correlated to the density of $G$. aculeatus. Stepwise multiple linear regression on $\log (n+1)$ transformed data revealed a significant negative influence of $G$. aculeatus and $N$. integer on both $E$. affinis total density and the density of nauplii, while the contribution of fish $\times$ mysid was positive. In contrast, the density of the advanced stages of $E$. affinis was alone significantly negatively related to the density of $G$. aculeatus (Table 3).

Correlation analysis $[\log (n+1)$ transformed data] revealed a highly positive relationship between chl $a$ and the Neomysis integer density, but only a moderately negative relationship to Eurytemora affinis and no re- 
Table 2. Spearman correlation coefficients (with the statistical significance level in parentheses) based on log(n+1) transformed data collected on 7 sampling dates (30 July to 20 August) in 9 field enclosures. $\cdots, \cdots, \cdots$ represent the $0.05,0.01,0.001$ and 0.0001 significance levels, respectively. ns: not significant

\begin{tabular}{|c|c|c|c|c|c|c|}
\hline & \multirow{2}{*}{$\begin{array}{l}\text { Three-spined } \\
\text { sticklebacks }\end{array}$} & \multirow{2}{*}{$\begin{array}{c}\text { Neomysis } \\
\text { integer }\end{array}$} & \multicolumn{3}{|c|}{ Eurytemora affinis number } & \multirow{2}{*}{$\begin{array}{c}\text { E. affinis } \\
\text { Total biomass }\end{array}$} \\
\hline & & & Nauplii & Copepodites + adults & Total & \\
\hline$N$. integer & $-0.002^{\mathrm{ni}}$ & & & & & \\
\hline \multicolumn{7}{|l|}{ E. affinis number } \\
\hline Nauplii & $-0.27^{\circ}$ & $-0.46^{\cdots}$ & & & & \\
\hline Copepodites + adults & $-0.62 \cdots$ & $0.05^{\mathrm{ns}}$ & $0.49 \cdots$ & & & \\
\hline Total & $-0.59 \cdots$ & $-0.06^{\mathrm{ns}}$ & $0.67 \cdots$ & $0.97 \cdots$ & & \\
\hline \multicolumn{7}{|l|}{ E. alfinis } \\
\hline Total biomass & $-0.62 \cdots$ & $0.04^{\mathrm{ns}}$ & $0.52 \cdots$ & $0.99 \cdots$ & $0.98 \cdots$ & \\
\hline Chl a & $-0.03^{\mathrm{ns}}$ & $0.49 \cdots$ & $-0.32^{\bullet}$ & $-0.02^{\mathrm{ns}}$ & $-0.12^{\mathrm{ns}}$ & $-0.03^{n s}$ \\
\hline
\end{tabular}

lationship to Gasterosteus aculeatus density (Table 2). Stepwise multiple linear regression on $\log (n+1)$ transformed data revealed a highly significant relationship between chl a and $N$. integer density, and a slightly negative one to $E$. affinis density (Table 3 ).

\section{Predation experiments}

The predation experiments showed a positive relationship between naupliar density and the Neomysis integer specific predation rate (SPR) $\left(\mathrm{r}^{2}=0.89, \mathrm{p}<\right.$ 0.0001 , Pearson's correlation) (Table 4). The SPR on nauplii at $15^{\circ} \mathrm{C}$ changed from an average of 15 ind. mysid ${ }^{-1} h^{-1}$ at a density of 100 nauplii $\mathrm{l}^{-1}$ to an average of 52 ind. mysid ${ }^{-1} \mathrm{~h}^{-1}$ at a density of 400 nauplii $\mathrm{l}^{-1}$. SPR on the advanced stages of Eurytemora affinis was not influenced by changes in naupliar density, and remained constant at an average of 6 ind. mysid ${ }^{-1} h^{-1}$ ( $p>0.3$, Kruskal-Wallis). Moreover, the clearance rates were not influenced by changes in naupliar density ( $\mathrm{p}>0.3$, Kruskal-Wallis), probably indicating that the mysids catch the nauplii by 'filter feeding' (Gauld 1951). The average clearance rate was $0.341 \mathrm{mysid}^{-1}$ $\mathrm{h}^{-1}$ for nauplii and 0.081 mysid $^{-1} \mathrm{~h}^{-1}$ for copepodites + adults. The mysid preference value was 0.7 for nauplii and for advanced stages 0.3 , the values being unaffected by naupliar density ( $p>0.25$, Kruskal-Wallis).

\section{DISCUSSION}

Neomysis integer had 2 generations in Lake Ferring during the study year. Recruitment started in May and June when the winter generation reproduced, and the resultant spring-born first generation constituted the

Table 3. Stepwise multiple regression showing the relationship between $\log (n+1)$ transformed values of chl $a$, the density of nauplii, copepodites + adults (Cop.+adults) and all stages of Eurytemora affinis versus $\log (n+1)$ transformed values of E. affinis (only chl a), Neomysis integer and sticklebacks Gasterosteus aculeatus density, as well as date in the enclosure experiments in July and August. $, \cdots, \cdots, \cdots$ represent the $0.05,0.01,0.001$ and 0.0001 significance levels, respectively. ns: not significant

\begin{tabular}{|c|c|c|c|c|c|c|c|c|}
\hline & \multirow{2}{*}{$\begin{array}{c}\text { Chl } a \\
\left(\mu \mathrm{g} \mathrm{I}^{-1}\right)\end{array}$} & \multirow[t]{2}{*}{$F$} & \multicolumn{6}{|c|}{ Eurytemora affinis (ind. $\mathrm{l}^{-1}$ ) } \\
\hline & & & Nauplii & $F$ & Cop.+adults & F & Total & $F$ \\
\hline Intercept & 6.16 & $4544^{\cdots} \cdots$ & 3.29 & $60 \cdots$ & 4.46 & $561 \cdots$ & 5.18 & $426^{\cdots} \cdots$ \\
\hline E. affinis & -0.05 & $10^{*}$ & - & & - & & - & \\
\hline Neomysis integer & 0.21 & $19 \cdots$ & -3.42 & $24 \cdots$ & ns & & -1.76 & $8 \cdots$ \\
\hline Sticklebacks & ns & & -1.28 & $19 \cdots$ & -1.25 & $41 \cdots$ & -1.63 & $43^{\cdots} \cdot$ \\
\hline N. integer $\times$ fish & ns & & 2.49 & $9.5 \cdots$ & ns & & 2.02 & $8 \cdot \cdot$ \\
\hline Dates & & $11 \cdots$ & & $4.4^{*}$ & ns & & ns & \\
\hline 1 & 0.06 & & -0.05 & & & & & \\
\hline 2 & -0.11 & & 0.46 & & & & & \\
\hline 3 & 0.08 & & -0.12 & & & & & \\
\hline 4 & 0.19 & & 1.63 & & & & & \\
\hline 5 & 0.37 & & 1.02 & & & & & \\
\hline 6 & 0.25 & & -0.17 & & & & & \\
\hline Model $r^{2}$ & 0.67 & & 0.60 & & 0.40 & & 0.46 & \\
\hline df & 61 & & 61 & & 61 & & 61 & \\
\hline
\end{tabular}


Table 4. Mean $( \pm$ SD) specific predation rates, clearance rates and selectivity coefficient of Neomysis integer feeding at 3 different densities of Eurytemora affinis. Water volume was $1 \mathrm{l}$, incubation time $2 \mathrm{~h}$ at $15^{\circ} \mathrm{C}$ in subdued light, and mysid density $3 \mathrm{l}^{-1}$ NC: density change in controls during the experiment

\begin{tabular}{|c|c|c|c|c|c|}
\hline & $\begin{array}{l}\text { Inital density } \\
\text { (ind. }\left.\right|^{-1} \text { ) }\end{array}$ & $\begin{array}{l}\mathrm{NC} \\
\text { (ind. } \mathrm{l}^{-1} \text { ) }\end{array}$ & $\begin{array}{l}\text { Spec. predation rate } \\
\text { (ind. mysid }{ }^{-1} h^{-1} \text { ) }\end{array}$ & $\begin{array}{l}\text { Clearance rate } \\
\left(1 \text { mysid }^{-1} \mathrm{~h}^{-1}\right)\end{array}$ & $\begin{array}{l}\text { Selectivity } \\
\text { coefficient }\end{array}$ \\
\hline Nauplii & 100 & $2 \pm 1$ & $15 \pm 2$ & $0.38 \pm 0.18$ & $0.65 \pm 0.09$ \\
\hline $\begin{array}{l}\text { Copepodites + adults } \\
(\mathrm{n}=3)\end{array}$ & 100 & $0 \pm 2$ & $8 \pm 2$ & $0.11 \pm 0.05$ & $0.36 \pm 0.09$ \\
\hline Nauplii & 200 & $2 \pm 3$ & $26 \pm 6$ & $0.36 \pm 0.22$ & $0.75 \pm 0.11$ \\
\hline $\begin{array}{l}\text { Copepodites + adults } \\
(\mathrm{n}=9)\end{array}$ & 100 & $2 \pm 2$ & $5 \pm 4$ & $0.08 \pm 0.10$ & $0.25 \pm 0.11$ \\
\hline Nauplii & 400 & $3 \pm 14$ & $52 \pm 11$ & $0.30 \pm 0.17$ & $0.70 \pm 0.12$ \\
\hline $\begin{array}{l}\text { Copepodites + adults } \\
(n=6)\end{array}$ & 100 & $4 \pm 4$ & $6 \pm 3$ & $0.07 \pm 0.04$ & $0.30 \pm 0.12$ \\
\hline
\end{tabular}

summer generation that together with surviving individuals of the winter generation reproduced in July and August, thus providing the new winter generation. Because of the protracted reproduction period, it was difficult to follow the individual cohorts; however, the seasonal variation in mysid size distribution was identical with that observed for $N$. integer in other brackish lakes, both in Denmark (Kaiser 1978) and elsewhere (Kinne 1955, Mauchline 1971, Borghouts 1978, Mauchline 1980, Bremer \& Vijverberg 1982, Arndt \& Jansen 1986, Irvine et al. 1993).

Mysid density and biomass in Lake Ferring was high (maximum 0.8 ind. $\mathrm{l}^{-1}$, corresponding to 1250 ind. $\mathrm{m}^{-2}$ ), the maximum biomass being $1100 \mathrm{mg} \mathrm{DW} \mathrm{m}^{-2}$. Similar mysid density was observed by Irvine et al. (1993), whereas much lower values were recorded by Bremer \& Vijverberg (1982) and Arndt \& Jansen (1986). Even though daytime mysid density in Lake Ferring was high, it was probably considerably underestimated. The diurnal study revealed substantial diel vertical migration of $N$. integer, the catches in Breder traps located at the lake bottom being 2 - to 3 -fold greater in daytime than at night, and the vertical hauls being conversely 4 -fold less in daytime than at night. That mysids in shallow lakes undergo diurnal migration is well documented (Beattie \& de Kruijf 1978, Bremer \& Vijverberg 1982, Irvine et al. 1993), and the differences found between day and night hauls were comparable to those found in previous investigations (Grossnickle \& Morgan 1979, Nero \& Davies 1982, Irvine et al. 1993). Estimated mysid density (and hence potential mysid impact on zooplankton) may therefore be underestimated by a factor of 4 , the true density probably therefore being nearer 3 ind. $\mathrm{l}^{-1}$ at maximum.

The high mysid density in Lake Ferring may reflect the hypertrophic character of the lake and the low predation pressure by fish; the fish biomass is extremely low and exclusively dominated by sticklebacks that mainly prey on copepods and to a minor extent on juvenile Neomysis integer (M. Sondergaard \& $\mathrm{E}$. Jeppesen unpubl. obs.). High densities of $N$. integer (up to 13 ind. $1^{-1}$ ) have been found in other Danish hypertrophic brackish lakes in which fish biomass is low (Jeppesen et al. 1994). Moreover, the relationship between $N$. integer density and the biomass of fish caught in multiple mesh size gill nets is generally negative in Danish shallow brackish lakes (Jeppesen et al. 1994). The importance of fish is also evidenced by fish manipulation experiments undertaken in Lake Wolderwejd. The Netherlands, where removal of $75 \%$ of the planktivorous fish biomass resulted in a major increase in $N$. integer density (Meijer et al. 1994).

The estimated growth rates of the various Neomysis integer size groups and the seasonal dynamics are similar to those found in previous investigations (Bremer \& Vijverberg 1982, Asthorsson \& Ralph 1984, Arndt \& Jansen 1986). The validity of calculating mysid growth rates from field data was questioned by Asthorsson \& Ralph (1984) on the grounds that it is periodically difficult to follow the cohorts. On the other hand, growth rates calculated from laboratory experiments may be influenced by the experimental conditions. In comparison with laboratory growth rates, Arndt \& Jansen (1986) found higher rates in natural populations. Mysid production (not corrected for sampling error) was higher than $10 \mathrm{mg} \mathrm{DW} \mathrm{m}^{-2} \mathrm{~d}^{-1}$ during most of the summer, reaching $35 \mathrm{mg} D W \mathrm{~m}^{-2} \mathrm{~d}^{-1}$ in mid-July. Despite the much higher density in Lake Ferring, the level and seasonal variation in the $N$. integer $\mathrm{P} / \mathrm{B}$ ratio was comparable to that reported in other studies on $N$. integer (Bremer \& Vijverberg 1982, Arndt \& Jansen 1986).

As to whether a high density of Neomysis integer affects the population structure of its potential prey, Eurytemora affinis, the laboratory predation experiments showed that mysids had a selective preference for nauplii and that the predation potential was high, with 
maximum predation rates on nauplii and copepodites + adults of 52 and 8 ind. mysid ${ }^{-1} \mathrm{~h}^{-1}$, respectively. Converted to biomass, this amounts to a daily ration of approximately $360 \% \mathrm{~d}^{-1}\left(3.6 \mathrm{~g} \mathrm{DW} \mathrm{g}^{-1} \mathrm{DW}\right.$ $\left.\mathrm{d}^{-1}\right)$. These rates are similar to observations made in other laboratory studies on $N$. integer (Irvine et al. 1990 , 1993). If the in situ predation rate was really so high, mysids in Lake Ferring would exterminate the nauplii and copepodite populations in a few days. This also applies to the field enclosures with the highest densities of $N$. integer $\left(0.5\right.$ to 1 ind. $\left.1^{-1}\right)$. However, as the predator and prey species coexist in both the enclosures and the lake as a whole, the predation pressures found in the laboratory experiments must be overestimates. There are various possible explanations for this. Firstly, E. affinis may find it more difficult to escape predation in the experimental chambers than in the field. In the lake the $N$. integer seek refuge from fish predation by staying near the bottom during daytime, but at the same time thereby affording the pelagic $E$. affinis a higher chance of survival. Secondly, there are alternative food sources in the lake, $N$. integer being known to be omnivorous and also able to feed on detritus and algae (Mauchline 1971, Bremer \& Vijverberg 1982, Arndt \& Jansen 1986, Irvine et al. 1993). That this was the case in Lake Ferring was confirmed by qualitative analysis of $N$. integer gut contents: these consisted, apart from copepods, of cyanobacteria, chlorophytes and diatoms, as well as various zooplankton such as ciliates and rotifers. Fragments of vascular plants, pollen and detritus were also detected. Further evidence of omnivory is provided by the fact that $N$. integer would only be able to meet a maximum of $22 \%$ and as little as $6 \%$ when corrected for sampling error of its food energy requirements from E. affinis, if we assume a growth yield of approximately $20 \%$ for $N$. integer (as the production of $E$. affinis and $N$. integer was calculated to 2.5 and $2.2 \mathrm{~g} \mathrm{DW} \mathrm{m}^{-2} \mathrm{yr}^{-1}$, respectively). That the predation rates found in the laboratory studies are overestimates is further emphasized by the fact that a daily ration of $360 \% \mathrm{~d}^{-1}$ will result in a growth rate far exceeding that obtained from the lake data (Fig. 2), and considerably greater than that found in several other studies (Cooper \& Goldman 1980, Chigby \& Sibley 1994). As the mysids used in the laboratory studies were prefed with $E$. affinis, the possibility can be excluded that prestarvation could explain the high predation rates obtained.

The enclosure experiments showed that at natural lake densities, Neomysis integer had a significant negative effect on the abundance of nauplii as well as on the total number of Eurytemora affinis, but not on the number of copepodites + adults. In contrast, Gasterosteus aculeatus had a negative impact on all stages but particularly the advanced stages, as has been reported in many other studies (e.g. Worgan \& FitzGerald 1981,
Castonguay \& FitzGerald 1990, Pont et al. 1991). The contribution of sticklebacks $\times N$. integer in the multiple regression was positive for the nauplii (Table 3 ), however, which may be explained by the fact that $N$. integer seeks refuge from fish predation near the bottom (Meijer et al. 1994), thereby reducing the predation pressure on the nauplii, which typically inhabit pelagic waters

Since Neomysis integer and Gasterosteus aculeatus coexist in many hypertrophic brackish lakes, including Lake Ferring, it is therefore likely that the predation pressure on Eurytemora affinis in such lakes is particularly high, the E. affinis being preyed upon both from 'below' ( $N$. integer) and from 'above' (G. aculeatus). The coexistence of $N$. integer and sticklebacks may explain why the zooplankton grazing pressure on the phytoplankton is generally lower in hypertrophic brackish lakes, including Lake Ferring, than in corresponding freshwater lakes, where planktivorous fish are the exclusively dominant macropredator (Jeppesen et al. 1994)

In the enclosure experiments a highly positive correlation was found between chl a and Neomysis integer density. This may in part be explained by predation on the phytoplankton-grazing copepods since chl a and nauplii density were negatively correlated (Table 2). However, the correlation to $N$. integer was much stronger than to copepods. Moreover, the stepwise multiple regression showed that $N$. integer contributed highly significantly to residual variation in chl a when copepods were included in the model, while sticklebacks did not (Table 3 ). Similar results were obtained in enclosure experiments in another Danish brackish lake (F. Nielsen \& E. Jeppesen unpubl. obs.). These results suggested a more direct stimulation of phytoplankton growth by $N$. integer, perhaps because nutrients consumed when feeding on the sediment surface are subsequently excreted to the water above. In fact, the experiment by Nielsen \& Jeppesen (unpubl. obs.) showed markedly higher phosphorus levels in enclosures with $N$. integer. As the density in the enclosures (0.5 to 1 mysid $1^{-1}$ ) in Lake Ferring was comparable to that in the lake (Figs. 4 \& 5), it seems reasonable to suggest that mysids negatively influenced the environmental state of the lake in terms of higher algal biomass and consequently a lower Secchi depth. In support of this view multiple regression analysis of 3 years' data from the lake showed that besides being significantly negatively related to the total zooplankton biomass, chl a was positively related to the $N$. integer density (Nielsen \& Jeppesen unpubl. obs.).

Acknowledgements. We thank the technical staff at the National Environmental Research Institute for help with the study, Kathe Møgelvang for skilful drawings, Anne Mette 
Poulsen and Anne-Dorthe Matharu for editorial assistance, and Jane Stougaard-Pedersen, Birte Laustsen, Karina Jensen, John Glargaard, Lone Nørgaard \& Lissa Hansen for assistance in the field and in the laboratory. We also thank David Barry for revising the manuscript. The study was partly sponsored by the European Community (NORSPA-programme) and by the Centre for Environmental Freshwater Research.

\section{LITERATURE CITED}

Arndt EA, Jansen W (1986) Neomysis integer (Leach) in the Chain of Boddens south of Darss/Zingst (Western Baltic) Ecophysiology and population dynamics. Ophelia 4:1-15

Asthorsson OS, Ralph R (1984) Growth and moulting of Neomysis integer (Crustacea: Mysidacea). Mar Biol 79:55-61

Bach F, Petersen A, Jacobsen H (1991) Metoder ved oparbejdning af plankton i Ferring Sø, Sondervese, Norrevese, Noret og Hygum Nor 1990. Report to Ringkjøbing County. Danish Health Society, Silkeborg

Beattie DM, de Kruijf H (1978) Population dynamics and biomass production of Neomysis integer (Leach) in the Bergumermeer. Verh int Verein theor angew Limnol 20: $2566-2571$.

Borghouts CH (1978) Population structure and life-cycle of Neomysis integer (Leach) (Crustacea, Mysidacea) in two types of inland waters. Verh int Verein theor angew Limnol 20:2561-2565

Bowers JA, Vanderploeg HA (1982) In situ predatory behavior of Mysis relicta in Lake Michigan. Hydrobiologia 93: $121-131$

Branstrator DK, Lehman JT (1991) Invertebrate predation in Lake Michigan: regulation of Bosmina longirostris by Leptodora kindtii. Limnol. Oceanogr. 36(3):483-495

Breder CN (1960) Design for a fry trap. Zoologica 45:155-160

Bremex P, Vijverberg J (1982) Production, population biology and diet of Neomysis integer (Leach) in a shallow Frisian lake (The Netherlands). Hydrobiologia 93:41-51

Castonguay M, FitzGerald GJ (1990) The ecology of the calanoid copepod Eurytemora affinis in salt marsh tide pools. Hydrobiologia 202:125-133

Chesson J (1978) Measuring preference in selective predation. Ecology 59(2): 211-215

Chigby P, Sibley TH (1994) Predation by Neomysis mercedis: effects of temperature, Daphnia magna size and prey density on ingestion rate and size selectivity. Freshwat Biol 32: $39-48$

Cooper SD, Goldman CR (1980) Opossum shrimp (Mysis relicta) predation on zooplankton. Can J Fish Aquat Sci 37:909-919

Fulton RS III (1983) Interactive effects of temperature and predation on an estaurine zooplankton community. J exp mar Biol Icol 72:67 -81

Gauld DT (1951) The grazing rate of planktonic copepods J mar biol Ass UK 29:695-706

Gliwicz ZM, Pijanowska I (1989) The role of predation in zooplankton succession. In: Sommer U (ed) Plankton ecology - succession in plankton communities. Springer-Verlag, New York, p 253-296

Goldman CR, Morgan MD, Threlkeld ST, Angeli N (1979) A population dynamics analysis of the cladoceran disappearance from Lake Tahoe, California-Nevada. Limnol Oceanogr 24(2):289-297

Grossnickle NE, Morgan MD (1979) Density estimates of Mysis relicta in Lake Michigan. J Fish Res Bd Can 36: $694-698$

Hanazato T (1990) A comparison between predation effects on zooplankton communities by Neomysis and Chaoborus. Hydrobiologia 198:33-40

Hansson S, Larsson U, Johansson S (1990) Selective predation by herring and mysids, and zooplankton community structure in a Baltic Sea coastal area. J Plankton Res 12:1099-1116

Higgins PJ (1985) An interactive computer program for popula-ion estimation using the Zippin method. Aquacult Fish Mgmt 1:287-295

Hirche HJ (1992) Egg production of Eurytemora affinis effect of k-strategy. Estuar coast Shelf Sci 35:395-407

Holm-Hansen O, Riemann B (1978) Chlorophyll a determination: improvements in methods. Oikos 30:438-447

Irvine K, Bales MT, Stansfield JH, Snook D (1990) Trophic relations in Hickling Broad - a shallow and brackish eutrophic lake. Verh int Verein theor angew Limnol 24: $576-579$

Irvine K, Moss B, Bales M, Snook D (1993) The changing ecosystem of a shallow, brackish lake. Hickling Broad, Norfolk, UK. I. Trophic relationships with special reterence to the role of Neomysis integer (Leach). Freshwat Biol 29:119-139

Jeppesen E, Søndergaard M, Kanstrup E, Petersen B, Eriksen RB, Hammershøj $M$, Mortensen $E_{\text {, Jensen JP, Have } A}$ (1994) Does the impact of nutrients on the biological structure and function of brackish and freshwater lakes differ? Hydrobiologia 275/276:15-30

Kaiser EW (1978) Storkrebs (Malocostraca) fra indvande i Thy og Vester-Hanherred. Zootopografiske undersegelser i Thy 14. Flora Fauna 84:3-28

Kinne $O$ (1955) Neomysis vulgaris Thompson, eine autökologisch-biologische Studie. Biol Zbl 74:160-202

Langeland A (1988) Decreased zooplankton density in a mountain lake resulting from predation by recently introduced Mysis relicta. Verh int Verein theor angew Limnol 23:419-429

Mauchline J (1971) The biology of Neomysis integer (Crustacea, Mysidacea). J mar biol Ass UK 51:347-354

Mauchline $J(1980$ ) The biology of mysids and euphausiids. In: Blaxter JHS, Russel FS, Yonge $M$ (eds) Advances in marine biology 18. Academic Press, London, p 1-677

Meijer ML, van Nes EH, Lammens EHRR, Gulati RD, Grimm MP, Backx J, Hollebeek P, Blaauw EM, Breukelaar AW (1994) The consequences of a drastic fish stock reduction in the large shallow Lake Wolderwijd. The Netherlands. Can we understand what happened? Hydrobiologia 275/ $276: 457-466$

Moss B (1994) Brackish and freshwater shallow lakes - different systems or variations on the same theme? Hydrobiologia $275 / 276: 1-14$

Moss B, Leah RT (1982) Changes in the ecosystem of a guanotrophic and brackish shallow lake in eastern England: potential problems in its restoration. Int Revue ges Hydrobiol 67(5):625-659.

Nero RW, Davies IJ (1982) Comparison of two sampling methods for estimating the abundance and distribution of Mysis relicta. Can J Fish Aquat Sci 39:349-355

Pont D, Crivelli AJ, Guillot F (1991) The impact of threespined sticklebacks on the zooplankton of a previously fish-free pool. Freshwat Biol 26:149-163

Rudstam LG, Hansson S, Larsson U (1986) Abundance, species composition and production of mysid shrimps in a coastal area of the Northern Baltic Proper. Ophelia $4: 225-238$

Worgan JP, FitzGerald GJ (1981) Diel activity and diet of three sympatric stıcklebacks in tidal salt marsh pools. Can J Zool 59:2375-2379 